\title{
A GESTÃO DOS RESÍDUOS SÓLIDOS EM SANTO ANASTÁCIO, SÃO PAULO, BRASIL: UMA ANÁLISE DO PLANO MUNICIPAL.
}

\author{
Bruna Dienifer Souza Sampaio \\ Universidade Estadual Paulista - UNESP, Mestrado no Programa de Pós Graduação em Geografia, Presidente \\ Prudente, SP. E-mail: bruna jenny@hotmail.com.
}

\section{RESUMO}

O presente trabalho tem como objetivo analisar o Plano de Gerenciamento Integrado de Resíduos Sólidos de Santo Anastácio - SP, a fim de debater sobre a gestão ambiental no município e sua aplicação, especialmente em relação aos resíduos sólidos. A metodologia consistiu em leituras sobre planejamento e gestão ambiental e teve como base a Política Nacional de Resíduos Sólidos que rege os demais Planos, além da realização de trabalho de campo nos órgãos públicos para coleta de informações. Os resultados indicam a existência do Plano que prevê a implantação da coleta seletiva com a inclusão de catadores de materiais recicláveis, porém até o momento não existe ações para a concretização da proposta. Faz-se necessário planejar as ações com todas as etapas para a aplicação do Plano com o proposito de melhorar a gestão ambiental e a qualidade socioambiental.

Palavras-chave: Planejamento, Gestão, Plano municipal, Resíduos Sólidos, Santo Anastácio.

\section{THE MANAGEMENT OF SOLID WASTE IN SANTO ANASTÁCIO, SAO PAULO, BRAZIL: AN ANALYSIS OF THE MUNICIPAL PLAN.}

\begin{abstract}
This study aimed to analyze the Integrated Management Plan for Waste Solid Santo Anastacio - SP, in order to discuss the environmental management in the city and its application, particularly in relation to solid waste. The methodology consisted of readings on environmental planning and management and was based on the National Solid Waste Policy that governs the other plans, in addition to conducting field work in public agencies to collect information. The results indicate the existence of the Plan provides for the implementation of selective collection with the inclusion of recycling pickers, but to date there is no action for the implementation of the proposal. It is necessary to plan the actions with all steps for the implementation of the Plan with the purpose of improving environmental management and environmental quality.
\end{abstract}

Keywords: Planning, Management, Municipal Plan, Solid Waste, Santo Anastacio. 


\section{INTRODUÇÃO}

A questão ambiental dos resíduos sólidos urbanos é um assunto amplamente discutido na atualidade, devido aos problemas ambientais advindos do aumento da população global que consome cada vez mais bens e produtos e consequentemente gera mais lixo que é descartado na natureza.

A natureza ou o meio físico é a base de suporte para a vida no Planeta, é dela que tiramos os recursos naturais para transformar em bens de consumo que após a sua utilização retorna na forma de resíduos sólidos no meio ambiente. Esses resíduos disposto inadequadamente no meio físico demora muito tempo para se decompor, pois o ritmo do sistema de produção é acelerado e o ritmo da natureza em "digerir" os resíduos sólidos é mais lento.

Além da degradação ambiental ocasionada pela disposição irregular de resíduos sólidos no meio ambiente, existe o fator social dessas interrelações, discutidas por Figueiredo (1995) e Mazzini (1997) e abordada na Política Nacional de Resíduos Sólidos (PNRS), no que diz respeito às pessoas que sobrevivem "do lixo" - conhecidas como catadores ${ }^{1}$ de materiais recicláveis.

A Política Nacional de Resíduos Sólidos (PNRS) ${ }^{2}$, Lei № 12.305/2010 contem instrumentos para enfrentar os problemas decorrentes do manejo inadequado de resíduos sólidos, sendo a política maior/prioritária do país e a base para os demais planos municipais acerca da gestão dos resíduos (ver Figura 2 sobre a hierarquização das leis).

Para este trabalho utilizamos como referência o Plano Municipal de Gerenciamento Integrado de Resíduos Sólidos de Santo Anastácio (PGIRSA) que contem as medidas políticas, técnica, administrativa e econômica para reestruturação das atividades que envolvem os resíduos sólidos. Qual é a situação atual da gestão dos resíduos sólidos no município de Santo Anastácio? Como foi elaborado o Plano de Gerenciamento Integrado de Resíduos Sólidos de Santo Anastácio? O Plano municipal foi implementado?

Diante essas reflexões, este trabalho tem como objetivo discutir sobre a gestão dos resíduos sólidos no município de Santo Anastácio - SP, a fim de evidenciar a realidade praticada e a perspectiva (ideal).

\section{METODOLOGIA}

Para construir a base teórica de discussão acerca do tema foi realizada uma revisão bibliográfica sobre o planejamento e a gestão ambiental, a Política Nacional de Resíduos Sólidos, Lei № 12.305/2010 e a análise do Plano Municipal de Resíduos Sólidos Urbanos de Santo Anastácio (SP). Além disso, houve a pesquisa em campo nos órgãos municipais para busca de informações diretas sobre a gestão e gerenciamento dos resíduos sólidos.

\section{RESULTADOS}

O conceito de gestão de resíduos sólidos abrange as atividades referentes às estratégias com relação aos aspectos institucionais, administrativos, operacionais, financeiros e ambientais, é a organização do setor, envolvendo políticas, instrumentos e meios (LIMA, 2001, p.21, grifo nosso).

O município de Santo Anastácio localiza-se no interior do Estado de São Paulo, possui uma população de 20.475 habitantes, tem uma área da unidade territorial de $552,537 \mathrm{Km}^{2}$ (IBGE, 2010). Em Santo Anastácio, a população produz e descarta $356,400 \mathrm{~kg}$ por mês de resíduos domiciliar e comercial, cada habitante da área urbana produz e destina ao aterro 0,720 kg de resíduos por dia, esses resíduos domiciliares são depositados em Aterro Sanitário em sistema de valas (SAMPAIO; TROMBETA; LEAL, 2015).

\footnotetext{
${ }^{1}$ Ver trabalho publicado na Revista Pegada (.15, p. 167-186, 2015): Catadores de materiais recicláveis no município de Santo Anastácio, São Paulo: consumismo e precarização do trabalho.

${ }^{2}$ http://www.planalto.gov.br/ccivil_03/_ato2007-2010/2010/lei/I12305.htm
} 
Como infraestrutura para o serviço de limpeza urbana o município possui cinco veículos, dos quais dois são caçambas sem compactação e três são com compactação. Na coleta há dez funcionários; na capina e varrição (e na limpeza de bueiros) há oito funcionários.

A gestão integrada de resíduos sólidos é um "conjunto de ações voltadas para a busca de soluções para os resíduos sólidos, de forma a considerar as dimensões política, econômica, ambiental, cultural e social, com controle social e sob a premissa do desenvolvimento sustentável" (Lei 12.305/2010).

O Plano de Gerenciamento Integrado de Resíduos Sólidos de Santo Anastácio (PGIRSSA) foi elaborado por uma empresa de consultoria privada juntamente com a Prefeitura Municipal e por intermédio da Secretaria de Agricultura e Abastecimento.

A estrutura do PGIRSSA consiste na caracterização do município, no aspecto histórico e físico; possui um Contexto sobre o gerenciamento de Resíduos Sólidos Urbanos (RSU), objetivos (gerais e específicos) do Plano; Serviço de Limpeza Pública e Tratamento dos Resíduos Sólidos; Adequação da Operacionalidade da Disposição Final do Lixo; Resíduos Sólidos e a Responsabilidade do Gerador; Sucesso na Implementação; compreende as definições e classificação dos resíduos; Proposta metodológica de coleta das informações; Diagnóstico; Prognóstico; Planos de Metas; fontes obtenção de Recursos Financeiros para aquisição de equipamentos para limpeza pública e coleta seletiva; Situações de Emergência e contingência; Monitoramento e avaliação das medidas e das ações implementadas.

A elaboração desse Plano significa um avanço do município em busca de recursos financeiros para implantação da coleta seletiva com a inclusão de catadores de material reciclagem. Porém, até o presente momento não há, de fato, a coleta seletiva no município de Santo Anastácio.

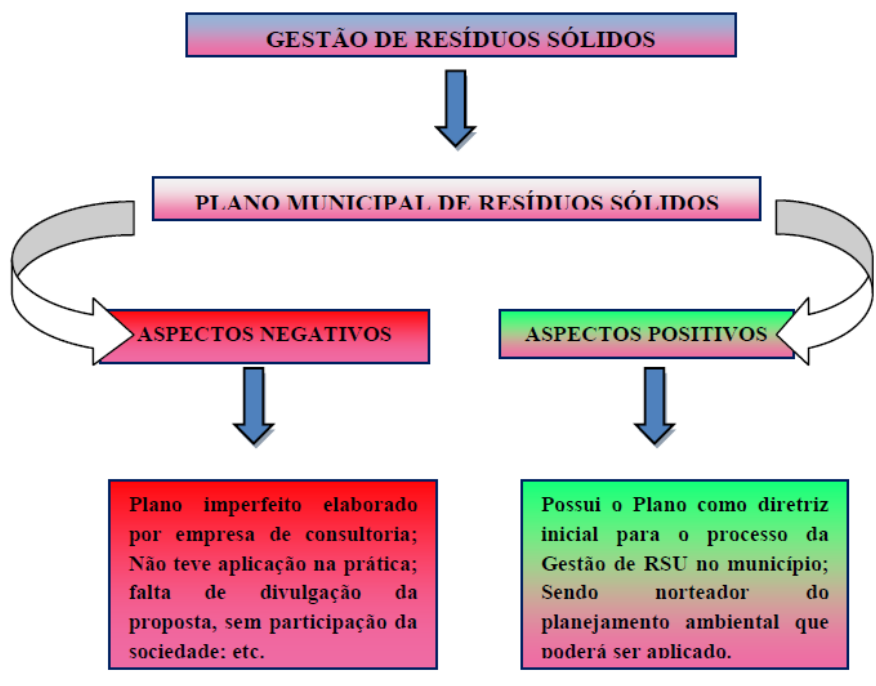

Organização: SAMPAIO, B. D. S (2016).

Figura 01. Debilidades e melhorias na Gestão de RSU em Santo Anastácio.

Atualmente, o poder público municipal busca contratos para a execução das obras de intervenções em coleta e tratamento de resíduos sólidos, com a coleta seletiva e o centro de triagem de materiais recicláveis. Através da elaboração e aprovação do Plano Municipal de gerenciamento de resíduos sólidos, o município de Santo Anastácio receberá da Caixa a quantia do "Programa de Compensação Ambiental" para implantar a coleta seletiva e construí o barracão de triagem dos materiais recicláveis, e assim, minimizar os problemas socioambientais advindos da problemática do "lixo". 


\section{DISCUSSÃO}

O Planejamento é um instrumento fundamental para a tomada de decisões e implementações de ações nas esferas sociais e econômicas. O Planejamento é a forma de pensar, de conseguir que as políticas sejam compreensivas, a fim de concentrar as metas e decisões coletivas, de médio a futuro prazo, além de prever e manejar a incerteza. Assim, o planejamento ambiental é à base do Planejamento Territorial, visto que a natureza é a base que dá suporte à vida na terra.

Para Rodriguez (2002) o objeto do Planejamento Ambiental é o meio ambiente - os sistemas ambientais. As regiões geográficas, os ecossistemas, as áreas urbanas são exemplos de sistemas "estáveis", porém estão em permanentes transformações e renovações, e à medida que se introduz elementos na sua interação ocorrem instabilidades no sistema, como por exemplo, o desejo de resíduos sólidos (esgoto in natura) no recurso hídrico que altera a qualidade da água na bacia hidrográfica afetando todas as comunidades do ecossistema aquático.

La Planificación Ambiental, se ha ido considerando desde sus inicios como uma material fundamentalmente centrada em los fenómenos naturales (de índole ecológica y geográfica). Sin ebargo, cada vez más en los útimos años se acepta que la inclusión de la compleja problemática política, económica y social que atravesa la población debe ser el punto de partida para cuaquier planeación y gestión ambiental (RODRIGUEZ, p.40, 2002, grifo nosso).

O Planejamento Ambiental é fundamental tanto na perspectiva teórica como na prática (SANTOS, 2004, p.19), é um processo ligado a qualquer tomada de decisão na esfera social, econômica e territorial (RODRIGUEZ, 2002). O Planejamento Ambiental tem um caráter democrático, considerado por Rodriguez (2002) como um processo dinâmico e permanente de participação da população, dos agentes econômicos e politico com diferentes discussões de ideais e opiniões. Assim, o Planejamento Ambiental tem como objetivo cumprir com os princípios relacionados ao meio ambiente.

A Gestão Ambiental é definida como "la conducción, dirección, control y administración del uso del território, através de determinados instrumentos, regulamentos, normas, financiamento y disposiciones institucionales y jurídicas" (RODRIGUEZ, 2002). Assim, a gestão ambiental deve estar articulada com a Gestão Territorial porque faz parte da mesma. Portanto, a Gestão e o Planejamento Ambiental são instrumentos importantes que são orientados pela/dentro da Política Ambiental.

Em relação à estrutura hierárquica das políticas de resíduos sólidos no Brasil, tem-se a Política Nacional de Resíduos Sólidos (PNRS), Lei 12.305/2010 (Decreto 7.404/2010) tem por objetivo a eliminação dos lixões, a disposição adequada dos rejeitos, com novos cenários para o Brasil (art. 9). Como resultado deu-se a elaboração de planos nacionais, planos estaduais e metas para elaboração de planos municipais de resíduos sólidos para uma gestão integrada dos resíduos no país. Para isso deve-se fazer um diagnóstico pormenorizado, propor soluções regionalizadas, recuperar áreas degradadas e fazer o reaproveitamento energético (art.8). São inúmeros os objetivos estabelecidos no PNRS (art.7), dentre eles: proteger a saúde pública e meio ambiente; incentivar a não geração de resíduos, redução, reutilização e reciclagem; buscar tecnologias mais limpa; integrar os catadores na reciclagem e incentivar a aquisição de produtos reciclados; realizar o gerenciamento integrado dos resíduos sólidos e capacitar técnicos na área de resíduos sólidos.

O Plano Estadual de Resíduos Sólidos ${ }^{3}$ (PERS) atende ao conteúdo previsto na Política Nacional, especificadamente o Plano de Resíduos do Estado de São Paulo que teve apoio da

\footnotetext{
${ }^{3}$ Lei 12.300/2006 (Decreto 54.645/2009) busca o tratamento e disposição adequada dos resíduos como a elaboração do diagnóstico, com meios para controlar e fiscalizar, e implantar da logística reversa. Site: http://s.ambiente.sp.gov.br/cpla/plano-residuos-solidos-sp-2014.pdf 
Secretaria do Meio Ambiente (SMA) e da Companhia Ambiental do Estado de São Paulo (CETESB) enfatiza a situação da gestão e o gerenciamento dos resíduos sólidos (Panorama dos Resíduos); o Estudo de Regionalização e Proposição de Arranjos Intermunicipais para fomentar a descentralização das políticas públicas ${ }^{4}$; a Proposição de Cenários, que busca a visualização de possíveis configurações futuras para os resíduos sólidos, a partir de projeções de geração; e as Diretrizes, Metas e Ações para propor estratégias em médio prazo (10 anos) a fim de assegurar a implementação do Plano Estadual; e o Planejamento participativo com participação da sociedade por meio de consultas e Audiências públicas do Plano, nas regiões do Estado de São Paulo, estas foram fundamentais para construção conjunta e aperfeiçoamento do Plano de forma participativa e transparente. Portanto, o Plano Estadual adota a hierarquização na gestão e gerenciamento de resíduos sólidos - não geração, redução, reutilização, reciclagem, tratamento e disposição final adequada dos rejeitos.

Além disso, o Plano Municipal de Resíduos Sólidos Urbanos (PMRSU) é uma condição para obter os recursos da União e do Estado, tendo como responsável o titular do Sistema de Limpeza Urbana (SLU) municipal. O Plano Municipal deve incentivar iniciativas para a recuperação de áreas e passivos ambientais e o desenvolvimento de tecnologias para o reaproveitamento dos resíduos sólidos. Por exemplo, na coleta seletiva é dever do cidadão participar, interagir e incentivar, bem como, segregar, acondicionar e disponibilizar os resíduos adequadamente. É proibido lançar resíduos sólidos em corpos d'águas, dispor e queimar resíduos sólidos a céu aberto, praticar a catação em locais de disposição final dos resíduos sólidos, a importação de resíduos sólidos perigosos.

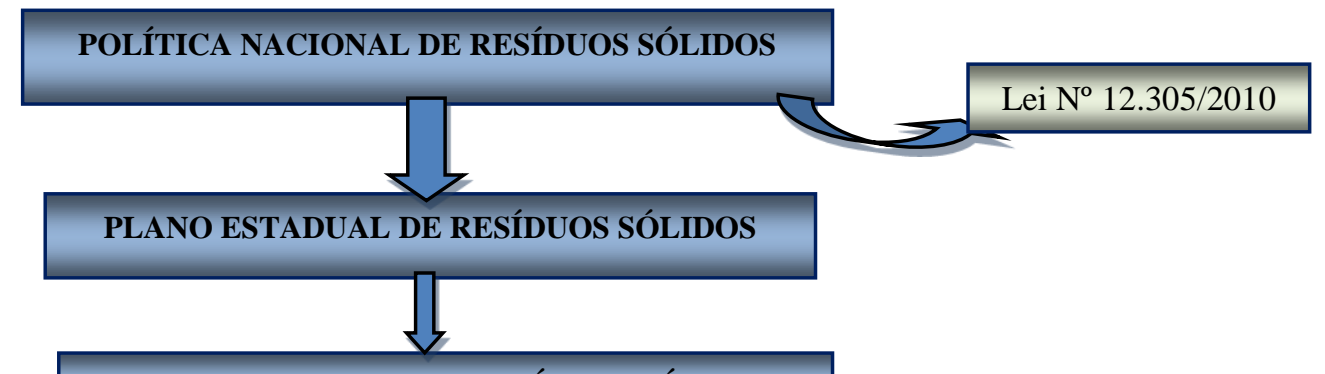

PLANO MUNICIPAL DE RESÍDUOS SÓLIDOS

Organização: SAMPAIO, B. D. S (2016).

Figura 02. Hierarquização das leis que regulamenta a Gestão de Resíduos Sólidos no Brasil.

\section{CONCLUSÃO}

O Planejamento é a primeira fase para a identificação e compreensão do problema relacionado aos resíduos sólidos, abrangendo o diagnóstico da realidade, o envolvimento com o problema e o desenvolvimento de propostas de solução.

O Plano Municipal é o caminho para a gestão ambiental, mas nada adianta se não for colocado em prática. A partir do diagnóstico dos resíduos sólidos urbanos no município é possível planejar as ações, pois, o diagnóstico é apenas uma etapa, de conhecer a área e propor melhorias, rumo ao desenvolvimento local mais sustentável. Nessa etapa de diagnóstico é a parte fundamental do Planejamento, pois deverá conter as alternativas utilizadas para a coleta e transporte dos diversos resíduos e a estimativa de participação de cada agente quanto aos volumes transportados no município, assim como, o índice de cobertura que a coleta atinge e os tipos de veículos utilizados (que mostramos no trabalho), isso induz a uma análise pormenorizada da situação de todos os tipos de resíduos que ocorrem localmente.

\footnotetext{
${ }^{4}$ Arranjos Institucionais voltados à gestão dos resíduos sólidos e o compartilhamento de serviços e atividades de interesse comum aos municípios, a fim de permitir a otimização dos recursos - financeiros, materiais e humanos.
} 
Além disso, é necessário investir em Educação Ambiental (em todos os setores da sociedade) de forma massiva porque as pessoas ainda possuem o hábito de destinar os resíduos, de forma clandestina e irregular, em áreas abandonadas que permanece em constante degradação.

Deve-se incorporar a sustentabilidade ambiental ao processo de desenvolvimento. Apesar de existir diferentes procedimentos de Planejamento e Ordenamento Ambiental, para sair da crise ambiental e civilizatória, deve-se abordar a temática ambiental a partir de novas perspectivas e domínio teórico-metodológico em busca de uma Educação Ambiental Renovada (RODRIGUEZ, p.8,2011).

Por fim, o Plano de Gerenciamento de Resíduos Sólidos ${ }^{5}$ é o instrumento de responsabilidade socioambiental na administração pública que deve ser bem elaborado e que de fato seja aplicado. Por isso, o Ministério do Meio Ambiente possui um modelo para facilitar a elaboração dos Planos a fim de aperfeiçoar a gestão e o gerenciamento dos resíduos sólidos, e contribuir para um país mais sustentável, portanto, a sociedade deve atuar de forma participativa e cobrar dos órgãos competentes a sua aplicação.

\section{AGRADECIMENTOS}

À Profa. Dra. María Gloria Fabregat Rodríguez por ter ministrado a disciplina de tópico especial Desarrollo y sostenibilidad ambiental: los resíduos sólidos urbanos em la gestion ambiental, e ter transmitido o conhecimento sobre a Política e a Gestão Ambiental referente aos Resíduos Sólidos Urbanos (RSU) de Cuba e ao CNPq pelo financiamento.

\section{REFERÊNCIAS}

CAMPOS, JAYME DE OLIVEIRA; BRAGA, ROBERTO; CARVALHO, POMPEU FIGUEIREDO DE. Manejo de Resíduos: pressupostos para a gestão ambiental. Rio Claro: Laboratório de Planejamento Municipal- Deplan- IGCE, UNESP, 2002. 112p.: il.

FIGUEIREDO, P.J.M. A sociedade do lixo: os resíduos, a questão energética e a crise ambiental. 2ª ed. Piracicaba: UNIMEP, 1995.

LEAL, A. C, et al. Resíduos Sólidos no Pontal do Paranapanema. Presidente Prudente: Centelha, 2004.

LIMA, José Dantas de. Gestão de resíduos sólidos urbanos no Brasil. João Pessoa: UFPB, 2001.

MAZZINI, Eliane de Jesus Teixeira. De lixo em lixo em Presidente Prudente (SP): novas áreas, velhos problemas. Monografia. Presidente Prudente: UNESP, 1997.

PLANO DE GERENCIAMENTO INTEGRADO DE RESÍDUOS DE SANTO ANASTÁCIO (PGIRSA), Santo Anastácio, SP, 2011.

PRESIDÊNCIA DA REPÚBLICA. Política Nacional de Resíduos Sólidos: Lei N 12.305/2010. Disponível em: <http://www.planalto.gov.br/ccivil_03/_ato2007-2010/2007/lei/l11445.htm>. Acesso em: 19 jun. 2016.

RODRIGUEZ, José Manoel Mateo. Planificación Ambiental. La Habana, 2002.

\footnotetext{
${ }^{5}$ http://www.comprasgovernamentais.gov.br/arquivos/cartilhas/cartilha_pgrs_mma.pdf

http://www.mpgo.mp.br/portal/arquivos/2015/01/28/16_42_43_117_ebook_residuos_solidos_2014.pdf 
. La Dimensión Espacial Del Desarrollo Sostenible: Una Visión Desde América Latina.

La Habana, 2011. [libro digital; 353f.]

SAMPAIO, B. D. S. Pesquisa mostra falta de coleta seletiva em Santo Anastácio. Jornal 'O Imparcial', Presidente Prudente, 14 jun. 2013.

SAMPAIO, B. D. S.; Trombeta, L. R. ; Leal. Catadores de Materiais Recicláveis no Município de Santo Anastácio, São Paulo: consumismo e precarização do trabalho. Revista Pegada Eletrônica (Online), v. V.15, p. 167-186, 2015.

SCARLATO, Francisco Capuano; PONTIN, Joel. Do nicho ao lixo: ambiente, sociedade e educação. São Paulo: Atual, 1992 (Série meio ambiente).

SIMAS, André Luiz Fernandes; PEREZ, Zuleica Maria de Lisboa [org. et al.]. Plano de resíduos sólidos do estado de São Paulo. Secretaria do Meio Ambiente do Estado de São Paulo, Coordenadoria de Planejamento Ambiental, CETESB ; 1a ed. - São Paulo: SMA, 2014. 1 arquivo de texto (350 p.) : il. color., PDF; $160 \mathrm{MB}$ 